\title{
Echocardiographic Assessment of Right Ventricular Obstruction in Hypertrophic Cardiomyopathy
}

\author{
Masatoshi Shimizu, MD; Hiroya Kawai, MD; \\ Yoshiyuki Yokota, MD; Mitsuhiro Yokoyama, MD
}

\begin{abstract}
Echocardiography was used to evaluate the incidence, flow dynamics and morphological characteristics of right ventricular obstruction in 91 patients with hypertrophic cardiomyopathy. Color flow mapping was used to define the sites of obstruction in the left and right ventricles. Ventricular obstruction was considered to be present if the flow velocity was less than $2.0 \mathrm{~m} / \mathrm{s}$ as measured by continuous wave Doppler. The thickness of both the right ventricular free wall and anterior ventricular septum was measured to assess the magnitude and extent of hypertrophy. Right ventricular obstruction was present in 14 patients of whom $6(43 \%)$ had left ventricular obstruction also. The right ventricular obstructions were found in the outflow tract (9 patients), mid-base septal bulge (2 patients) and apical trabecular region (3 patients). Doppler waveform was confined to systole in all patients with obstruction in the outflow tract and in one of the patients with mid-base septal bulge. Moreover, the flow wave persisted into early diastole in 4 patients, including 2 with apical trabecular obstruction. The thickness of both the right ventricular free wall and anterior ventricular septum suggested that these hypertrophied regions were the sites of right ventricular obstruction. Thus, echocardiography was useful in evaluating right ventricular obstruction in hypertrophic cardiomyopathy. (Circ J 2003; 67: 855-860)
\end{abstract}

Key Words: Echocardiography; Hypertrophic cardiomyopathy; Right ventricular obstruction

$\mathbf{S}$ ystolic pressure gradients within the right ventricular cavity have been demonstrated in some patients with hypertrophic cardiomyopathy $(\mathrm{HCM}) !^{1-6} \mathrm{~A}$ right ventricular obstruction in the right ventricular outflow tract has been reported, ${ }^{4}, 5$ and others have emphasized that the obstruction was predominantly present in the apex of the right ventricle 6,7 in these patients. Most of these observations have been derived from cardiac catheterization studies, which has its own limitations such as the difficulty in determining the exact site of obstruction in the right ventricle because of catheter entrapment in areas of cavity obliteration 8 and a selection bias to severely symptomatic patients. Echocardiography has recently become an important tool in evaluating patients with HCM. Two-dimensional (2-D) and Doppler echocardiography have been used in combination to non-invasively obtain morphologic and hemodynamic information. Doppler echocardiography has proved useful in determining the exact sites of obstruction $^{9,10}$ and in estimating pressure gradients ${ }^{11,12}$ in patients with left ventricular obstruction, but few studies have used this strategy to investigate right ventricular obstruction. Therefore, using the combined echocardiographic technique, we evaluated the incidence, flow dynamics and morphological characteristics of right ventricular obstruction in patients with HCM.

(Received April 18, 2003; revised manuscript received July 1, 2003; accepted July 28, 2003)

Division of Cardiovascular and Respiratory Medicine, Kobe University Graduate School of Medicine, Kobe, Japan

Mailing Address: Masatoshi Shimizu, MD, Department of Cardiology, Kobe National Hospital, 3-1-1 Nishi-ochiai, Suma-Ku, Kobe 654-0155, Japan. E-mail: simizum@nkh.hosp.go.jp

\section{Methods}

\section{Study Patients}

We evaluated data from 91 patients (59 men, 32 women; mean age, $47 \pm 16$ (range 17-74)) who met the set criteria for the diagnosis of HCM: symmetric or asymmetric hypertrophy of the left ventricle (maximum wall thickness $>15 \mathrm{~mm}$ ) without obvious causes of hypertrophy and a non-dilated left ventricular chamber. Patients with technically inadequate echocardiographic examinations were excluded from the study. Cardiovascular medications were withheld at least $24 \mathrm{~h}$ prior to echocardiographic examination.

\section{Echocardiographic Examination}

Echocardiographic examinations were performed using the commercially available Toshiba SSH $160 \mathrm{~A}$ system with a $2.5-\mathrm{MHz}$ transducer. Conventional 2-D echocardiograms were obtained in several cross-sectional planes using standard transducer positions. The magnitude and extent of hypertrophy in the left and right ventricles were assessed in parasternal long- and short-axis views, apical 4-chamber and right ventricular inflow views. End-diastolic wall

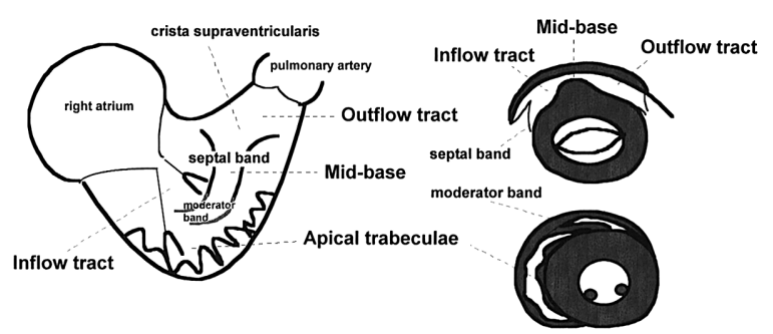

Fig 1. Schematic diagrams of the right ventricular obstruction and its relation to the right ventricular structures. 
Table 1 Clinical and Echocardiographic Features of Patients With Right Ventricular Obstruction

\begin{tabular}{|c|c|c|c|c|c|c|c|c|}
\hline \multirow{3}{*}{ Case no. } & \multirow{3}{*}{$\begin{array}{c}\text { Age } \\
\text { (years) }\end{array}$} & \multirow{3}{*}{$\operatorname{Sex}$} & \multicolumn{6}{|c|}{ Right ventricular obstruction } \\
\hline & & & \multirow{2}{*}{$\begin{array}{c}\text { NYHA } \\
\text { functional class }\end{array}$} & \multicolumn{4}{|c|}{ Continuous wave Doppler echocardiography } & \multirow[b]{2}{*}{ Termination phase } \\
\hline & & & & Region & $\begin{array}{l}\text { Peak velocity } \\
(\mathrm{m} / \mathrm{s})\end{array}$ & $\begin{array}{c}\triangle P G \\
(m m H g)\end{array}$ & $\begin{array}{l}\text { Duration } \\
\text { (ms) }\end{array}$ & \\
\hline 1 & 22 & $F$ & II & Outflow tract & 2.0 & 16 & 364 & Confined within systole \\
\hline 2 & 45 & $F$ & II & Outflow tract & 3.0 & 36 & 306 & Confined within systole \\
\hline 3 & 57 & $M$ & III & Outflow tract & 2.5 & 25 & 262 & Confined within systole \\
\hline 4 & 72 & $F$ & III & Outflow tract & 2.0 & 16 & 266 & Confined within systole \\
\hline 5 & 48 & $M$ & II & Outflow tract & 2.2 & 19 & 280 & Confined within systole \\
\hline 6 & 61 & $M$ & $I$ & Outflow tract & 3.3 & 44 & 392 & Confined within systole \\
\hline 7 & 47 & $M$ & II & Outflow tract & 3.2 & 41 & 304 & Confined within systole \\
\hline 8 & 42 & $M$ & $I$ & Outflow tract & 2.0 & 16 & 248 & Confined within systole \\
\hline 9 & 22 & $M$ & II & Outflow tract & 2.0 & 16 & 344 & Confined within systole \\
\hline 10 & 44 & $M$ & III & Mid-base & 2.8 & 31 & 412 & Isovolumic relaxation phase \\
\hline 11 & 30 & $M$ & $I$ & Mid-base & 2.1 & 18 & 364 & Confined within systole \\
\hline 12 & 45 & $M$ & II & Apical trabeculae & 2.0 & 16 & 500 & Early filling phase \\
\hline 13 & 45 & $M$ & II & Apical trabeculae & 2.1 & 18 & 384 & Isovolumic relaxation phase \\
\hline 14 & 38 & $M$ & $I$ & Apical trabeculae & 4.1 & 67 & 440 & Early filling phase \\
\hline
\end{tabular}

$\triangle P G$, Doppler estimated pressure gradients.

thickness of the right ventricular free wall and anterior ventricular septum were measured at the level of the chordae tendineae in the parasternal short-axis view. Color flow mapping was used to define the site of obstruction in the left and right ventricles as a high flow velocity signal, which was recognized as the zone of flow acceleration just proximal to the obstructive site and the turbulent jet just distal to it. Furthermore, in patients with right ventricular obstruction, the maximal end-diastolic wall thickness of the right ventricular free wall and interventricular septum were measured near the zone of flow acceleration. Continuous wave Doppler beam was directed toward the high flow velocity signal and the velocity profiles were recorded at a paper speed of $100 \mathrm{~mm} / \mathrm{s}$ for analysis. Doppler-estimated pressure gradient was determined using the modified Bernoulli equation: pressure gradient (in $\mathrm{mmHg}$ ) $=4 \mathrm{~V}^{2}$, where $\mathrm{V}$ is the maximal flow velocity (in $\mathrm{m} / \mathrm{s}$ ). Intraventricular obstruction was considered present if there was a high flow velocity signal of more than $2.0 \mathrm{~m} / \mathrm{s}$ in the left or right ventricular cavity. To describe the site of the right ventricular obstruction, the cavity was divided into four regions according to the right ventricular structures (Fig 1): (a) outflow tract region (just below the pulmonary valve at the crista supraventricularis); (b) mid-base region (at the septal band lying between the outflow tract and the inflow tract); (c) apical trabecular region (in the apical musculature comprised of the trabeculae, moderator band and papillary muscles); and (d) inflow tract region (just below the tricuspid valve). If there was left ventricular obstruction, it was identified as a sub-aortic outflow tract obstruction or a mid-ventricular obstruction according to the obstructive site $!^{3}$ Sub-aortic outflow tract obstruction was associated with systolic anterior motion of the mitral valves and the flow acceleration just proximal to the obstruction was seen in the outflow tract, whereas a mid-ventricular obstruction was accompanied by systolic apposition of the mid-ventricular walls at the papillary muscle level and the flow acceleration was seen in the mid ventricle.

\section{Statistical Analysis}

Data are presented as mean values \pm standard deviation. In patients with right ventricular obstruction, the paired ttest was used to compare the measurements at the site of ob- struction and at the chordae tendineae level. The unpaired t-test was used to compare data between patients with and without right ventricular obstruction. Differences between proportions were analyzed with the Chi-square test. A value of $\mathrm{p}<0.05$ was considered statistically significant.

\section{Results}

\section{Right Ventricular Obstruction}

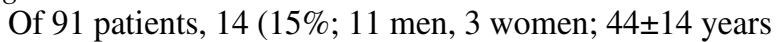
old) satisfied the set velocity criterion for right ventricular obstruction (Table 1). In patients with right ventricular obstruction, 4 were in New York Heart Association (NYHA)
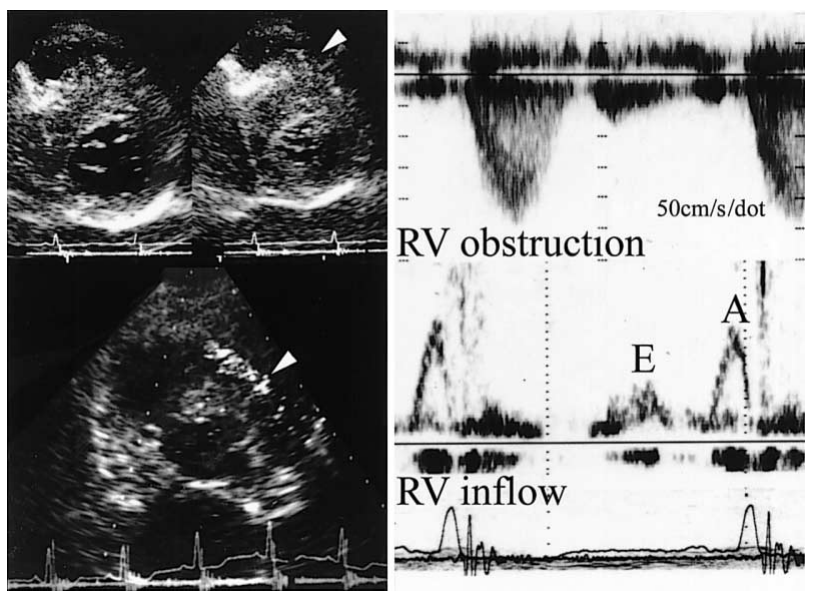

Fig 2. Representative 2-dimensional and Doppler echocardiograms in a patient with right ventricular outflow tract obstruction. (Upper left) Parasternal short-axis view shows that both the right ventricular free wall and the interventricular septum are prominently hypertrophied. Right ventricular outflow tract narrowing is apparent during systole (arrowhead). (Lower left) Color flow imaging of the right ventricular outflow tract demonstrates the site of obstruction as indicated by the zone of flow acceleration and the turbulent flow. The obstruction occurs just distal to the septal band (arrowhead). (Right) Continuous wave Doppler in the same area demonstrates a peak velocity of $2.5 \mathrm{~m} / \mathrm{s}$ consistent with a peak gradient of $25 \mathrm{mmHg}$. The gradient is confined within systole. RV, right ventricle; E, early filling wave; A, atrial filling wave. 


\begin{tabular}{|c|c|c|c|}
\hline \multicolumn{2}{|c|}{ Wall thickness } & \multicolumn{2}{|c|}{ Associated left ventricular obstruction } \\
\hline $\begin{array}{c}\text { Septum } \\
(\mathrm{mm})\end{array}$ & $\begin{array}{c}\text { Free wall } \\
(\mathrm{mm})\end{array}$ & $\begin{array}{c}\text { Subaotric } \\
\Delta P G(m m H g)\end{array}$ & $\begin{array}{l}\text { Mid-ventricle } \\
\triangle P G(m m H g)\end{array}$ \\
\hline 30 & 8 & 16 & 16 \\
\hline 29 & 7 & 16 & - \\
\hline 30 & 9 & - & - \\
\hline 22 & 9 & 20 & - \\
\hline 27 & 8 & - & - \\
\hline 24 & 8 & - & - \\
\hline 21 & 10 & - & - \\
\hline 22 & 8 & - & - \\
\hline 22 & 6 & - & - \\
\hline 27 & 11 & 36 & - \\
\hline 32 & 12 & 34 & 41 \\
\hline 29 & 12 & 53 & - \\
\hline 33 & 12 & - & - \\
\hline 23 & 10 & - & - \\
\hline
\end{tabular}

functional class I, 7 were in class II, and 3 were in class III. Five patients $(35.7 \%)$ had a family history of HCM in their first-degree relatives and all of them showed asymmetric hypertrophy of the left ventricle. Nine patients had right ventricular obstruction in the outflow tract region (Fig 2), while 2 obstructions were in the mid-base region at septal bulge (Fig 3) and 3 in apical trabecular region (Fig 4). None of the patients had right ventricular obstruction in more than 2 regions. The peak velocities ranged from 2.0 to 4.1 $(2.5 \pm 0.7) \mathrm{m} / \mathrm{s}$ and the velocity-derived peak systolic pressure gradients ranged from 16 to $67(27 \pm 15) \mathrm{mmHg}$. Furthermore, there were no high flow velocity signals in the inflow tract region.

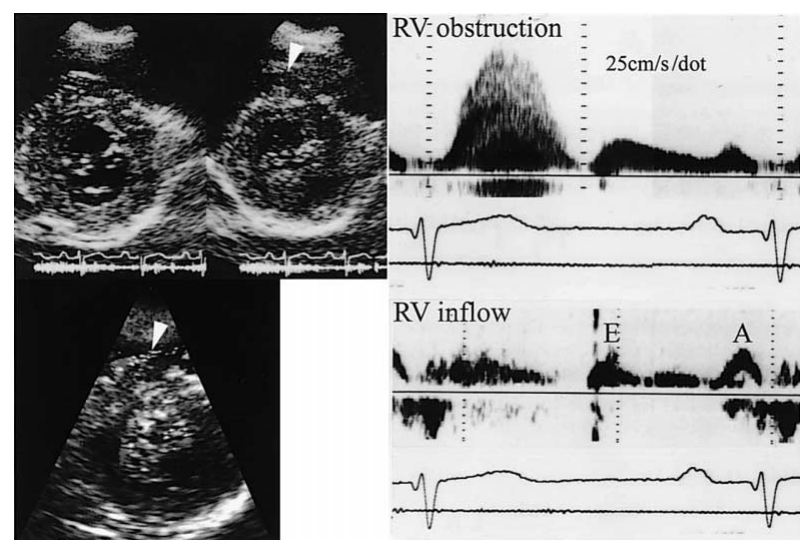

Fig 3. Representative 2-dimensional and Doppler echocardiograms in a patient with right ventricular mid-base obstruction. (Upper left) Parasternal short-axis view demonstrates prominent septal band and hypertrophied right ventricular free wall. The arrowhead shows apposition of the septal band and right ventricular free wall during systole, creating a right ventricular mid-base obstruction. (Lower left) Color flow imaging of the same area demonstrates the mid-base obstruction as indicated by the zone of flow acceleration just proximal to the septal band (arrowhead). (Right) Upper panel shows continuous wave Doppler recording of the mid-base obstruction, and lower panel shows pulsed wave Doppler recording of the right ventricular inflow waves. Continuous wave Doppler directed towards the flow acceleration demonstrates a peak velocity of $2.8 \mathrm{~m} / \mathrm{s}$ indicating a peak pressure gradient of $31 \mathrm{mmHg}$. The gradient persists into diastole until the beginning of early inflow wave; that is, the isovolumic relaxation phase.
In 77 patients without right ventricular obstruction, 39 were in NYHA functional class I, 36 were in class II, and 2 were in class III. In patients with right ventricular obstruction a significant number of them were classified as NYHA class III compared with patients without right ventricular obstruction $(\mathrm{p}<0.01)$. Thirty-two patients $(41.6 \%)$ without right ventricular obstruction had a family history of HCM.

\section{Associated Left Ventricular Obstruction}

Left ventricular obstruction was present in $27(30 \%)$ of the 91 patients in this study. Of the 14 patients analyzed for right ventricular obstruction, 8 patients had isolated right ventricular obstruction only and 6 patients had both right and left ventricular obstructions. The left ventricular obstruction was subaortic in 4 patients and both subaortic and mid-ventricular in the other 2 patients (Table 1 ). The latter 2 patients, therefore, had triple intra-ventricular obstructions including obstruction in the right ventricular cavity, left ventricular subaortic outflow tract and left mid-ventricle with no apparent relationships between the regions of right and left ventricular obstruction.

\section{Doppler Profiles}

The continuous wave Doppler flow velocity profiles showed a relatively symmetric and dome-like appearance in all patients with right ventricular obstruction. The waveform was confined to systole only in all of the 9 patients with right ventricular outflow tract obstruction (Fig 2) and 1 patient with a right ventricular mid-base obstruction. Furthermore, the flow wave persisted into early diastole in the remaining 4 patients, accounting for the total of 14 patients. Continuous wave Doppler signals lasted for 440 and $500 \mathrm{~ms}$ in each of the 2 patients with obstruction in the apical trabecular region, and the termination of the Doppler signals occurred later than the beginning of the rapid filling wave of the tricuspid inflow (Fig 5). There was a termination of the flow wave just before the beginning of the tricuspid rapid filling wave in the patients with obstruction in either the mid-base region (Fig 3) or the apical trabecular region. Because the flow velocity profiles were relatively symmetric, the time to the peak on the velocity profile was delayed in systole in patients with a flow wave extending into diastole.

\section{Wall Thickness}

The thicknesses of the interventricular septum and the
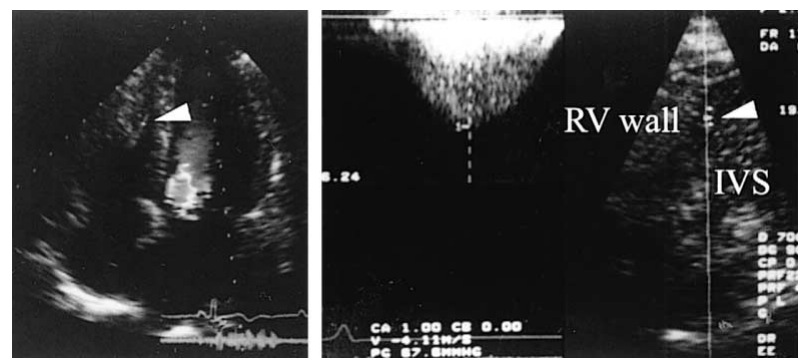

Fig 4. Representative 2-dimensional and Doppler echocardiograms in a patient with right ventricular apical trabeculae obstruction. (Left) Color flow imaging from the apical 4-chamber view reveals the site of obstruction as indicated by the turbulent flow in the apical trabeculae region (arrowhead). (Right) Continuous wave Doppler in the same area demonstrates a peak velocity of $4.1 \mathrm{~m} / \mathrm{s}$, consistent with a peak gradient of $67 \mathrm{mmHg}$. 


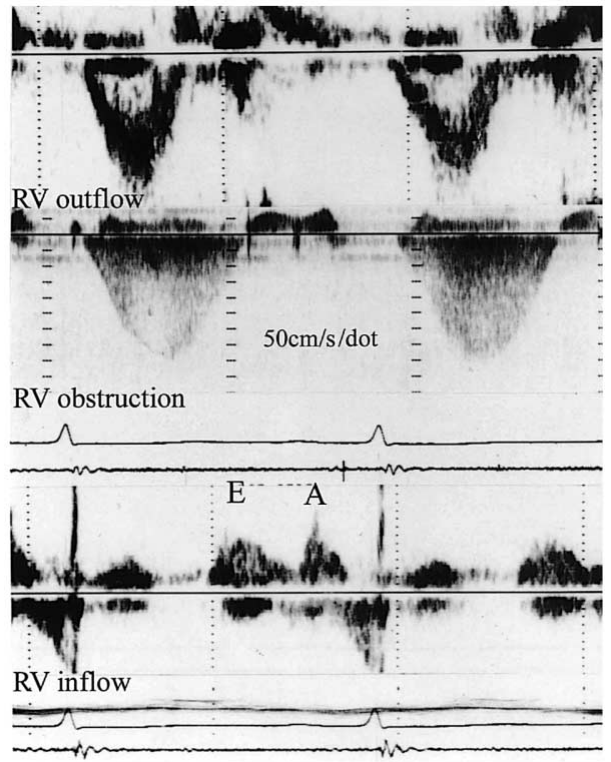

Fig 5. Representative Doppler recordings in a patient with right ventricular apical trabeculae obstruction. (Top) Pulsed wave Doppler recording of the right ventricular outflow tract. (Middle) Continuous wave Doppler recording of the right ventricular apical trabeculae obstruction. (Bottom) Pulsed wave Doppler recording of the right ventricular inflow tract. Continuous wave Doppler shows that the gradient is extending into diastole beyond the beginning of the early filling wave of the right ventricular inflow tract.

right ventricular free wall at the sites of obstruction were significantly greater than those measurements at the chordae tendineae level (Table 2) in patients with right ventricular obstruction. The thickness of the right ventricular free wall at the chordae tendineae level was greater in patients with right ventricular obstruction, but importantly there was no significant difference in the anterior ventricular septal thickness at the chordae tendineae level between patients with or without right ventricular obstruction.

\section{Discussion}

\section{Right Ventricular Obstruction in Hypertrophic Cardiomyopathy}

The results of our study show that right ventricular obstruction was present in 14 (15\%) of 91 patients with HCM. Patients with right ventricular obstruction had more severe symptoms than patients without right ventricular obstruction and its occurrence was independent of the family history of HCM. There has been little agreement on the incidence of right ventricular obstruction in patients with HCM; it has varied from $15 \%$ to $92 \%$ as documented by catheterization in previous studies! ${ }^{1,7}$ This extreme variabil- ity may be explained by the patients selected and the criteria of right ventricular obstruction defined in each study. Subjects in most of the previous studies were symptomatic patients with left ventricular obstruction and importantly patients without any symptoms or left ventricular obstruction were excluded. In the present investigation right ventricular obstruction was considered to be present if the peak flow velocity was more than $2.0 \mathrm{~m} / \mathrm{s}$ on continuous wave Doppler which, by simplified Bernoulli equation, amounts to more than $16 \mathrm{mmHg}$ compared with the previous studies that considered the presence of obstruction only at $7 \mathrm{mmHg}$ of pressure gradient in the right ventricle. Because echocardiography is a sensitive method for diagnosing HCM, the present study included not only symptomatic but also asymptomatic patients who had electrocardiographic abnormalities or cardiomegaly on chest radiography. The relatively mild clinical profiles of the patients partly explain the lower incidence of right ventricular obstruction in the present study compared with earlier studies.

\section{Regions of Right Ventricular Obstruction}

In our study the site of right ventricular obstruction was determined by dividing the right ventricular cavity into the outflow tract region, mid-base region and apical trabecular region. Mid-base obstruction at the septal band was distinguished from outflow tract obstruction just below the pulmonary valve as the septal band is located in the middle of the right ventricle between the pulmonary and tricuspid valves. Maron et al have shown that obstruction of the right ventricular outflow tract in HCM was associated with massive hypertrophy of the left ventricular musculature comprised of the crista supraventricularis, moderator band or trabeculae ${ }^{15}$ However, these previous studies have not been able to clarify the exact site of right ventricular obstruction and its correlation with the observed right ventricular structures. We found that mid-base obstruction in the right ventricle was characterized by a prominent hypertrophied septal band and associated with a zone of acceleration in the color flow mapping on the tricuspid valvular side of the septal band. Interestingly, significant hypertrophy of the crista supraventricularis and the associated zone of flow acceleration between the septal band and pulmonary valve were observed in patients with right ventricular outflow tract obstruction. Obstruction in the right ventricular apex was present in 3 of the present patients with HCM. Taylor et $\mathrm{al}^{16}$ used catheterization to show the existence of an obstructive pressure gradient between the lower and the upper segments of the right ventricle in patients with $\mathrm{HCM}^{16}$ and Lockhart et al recorded high pressures from the apex of the right ventricle in 11 of 12 patients with HCM6 The frequent occurrence of high pressures at the apex of the right ventricle in those previous studies could be attributable in part to cavity obliteration and entrapment of the

Table 2 Thickness of the Interventricular Septum and Right Ventricular Free Wall

\begin{tabular}{lcc}
\hline \hline & Interventricular septum (mm) & Right ventricular free wall $(\mathrm{mm})$ \\
\hline With right ventricular obstruction $(n=14)$ & $27 \pm 4$ \\
At the site of obstruction & $23 \pm 6-*$ \\
At the chordae tendinae level & $22 \pm 7$ \\
Without right ventricular obstruction $(n=77)$ & \\
At the chordae tendinae level &
\end{tabular}

${ }^{*} p<0.05,{ }^{\dagger} p<0.01$ compared with data at the site of obstruction, ${ }^{s} p<0.01$ compared with data in patients with right ventricular obstruction. 
catheter tip within a hypertrophied trabeculation. Color flow mapping has been used to detect left ventricular obstruction in either the outflow tract or in mid-ventricular region in patients with $\mathrm{HCM}^{9,10}$ and we used it as a powerful tool to assess right ventricular obstruction.

\section{Isolated Right Ventricular Obstruction}

Our present study showed that 6 of 14 patients with right ventricular obstruction had associated left ventricular obstruction: at the outflow tract in 4 patients and at that site as well as in the mid-ventricle in 2 patients. Although right ventricular obstruction in HCM is usually associated with left ventricular outflow tract obstruction, some cases of 'isolated' right ventricular obstruction have occasionally been described? $-5,7,14$ In the present study there were 8 patients with right ventricular obstruction only that warranted thorough examination using color flow mapping of the right ventricular cavity to identify the site of the obstruction, even in the absence of left ventricular obstruction. In fact, our results suggest that in patients with HCM color flow mapping of both the left and right ventricular cavities should be performed, irrespective of the presence of an obstruction in either cavity.

\section{Diastolic Flow in Right Ventricular Obstruction}

Continuous wave Doppler data showed that the flow velocity profiles continued into diastole in 4 patients with right ventricular obstruction and furthermore this flow wave exceeded the onset of the tricuspid rapid filling wave in 2 patients with obstruction at the right ventricular apex. Our data are comparable with those from the study by Zoghbi et al in patients with apical hypertrophy ${ }^{17}$ which characterized the presence of a diastolic high-velocity jet from the apex to the base with mid-left ventricular obstruction. The presence of a diastolic jet flow in mid-left ventricular obstruction is considered to be an important marker of concealed apical asynergy and a risk factor for adverse clinical events such as systemic embolism, ventricular tachycardia, and thallium perfusion abnormalities localized to the apical lesion ${ }^{18,19}$ It remains to be determined however, whether these complications also occur in patients with right ventricular apical obstruction who have demonstrated diastolic jet flow.

\section{Mechanisms of Right Ventricular Obstruction}

Our echocardiographic study showed increased thickness of the right ventricular free wall and interventricular septum, indicating that right ventricular obstruction was associated with muscular hypertrophy. McKenna et al showed that $44 \%$ of 73 patients with HCM had right ventricular hypertrophy as assessed by 2-D echocardiography, and furthermore, a right ventricular outflow tract gradient of more than $10 \mathrm{mmHg}$ was present in 6 of 48 patients as measured by cardiac catheterization ${ }^{20}$ Interestingly, the incidence of a right ventricular outflow gradient in patients with right ventricular hypertrophy was similar to that in patients without it. ${ }^{20}$ However, their study did not account for the contribution of regional right ventricular hypertrophy to right ventricular gradients; moreover, the pressure gradients in the right ventricular apex and mid-base region were not assessed ${ }^{20}$ Our data suggest that the narrowing of the right ventricular cavity by the hypertrophied right ventricular free wall and interventricular septum may contribute significantly to right ventricular obstruction in HCM.

Assessment of the Doppler flow velocity profiles may reveal right ventricular obstruction, which appears relatively symmetric and dome-like without the dagger-shaped profile characteristic of subaortic stenosis resulting from the dynamic stenosis caused by systolic anterior motion of the mitral valve and subsequent mitral-septal apposition.21 The symmetric flow velocity profiles that we recorded were similar to those observed in patients with mid-ventricular obstruction of the left ventricle ${ }^{22}$ which suggests that the pressure gradients in right ventricular obstruction are caused by a narrowing of the ventricular cavity because of muscle contraction during systole in addition to the hypertrophied right ventricular free wall and protruding interventricular septum. ${ }^{15}$

\section{Study Limitations}

Because $50 \%$ of the patients with right ventricular obstruction had an intra-cavity obstruction in the left ventricle, there was some difficulty in evaluating the clinical characteristics that could be attributed to right ventricular obstruction alone. We did not compare the pressure gradients estimated by Doppler with those obtained by catheterization because Doppler echocardiography is a very reliable method of detecting intra-cavity pressure gradients. In 3 patients with apical trabeculae obstruction there was a possibility of an overlap of the continuous wave Doppler signal by the tricuspid regurgitation signal because they were recorded concomitantly, but as the continuous wave Doppler signals exceeded the beginning of the tricuspid inflow wave, that possibility was overcome. Recently, the class I antiarrhythmic drug, cibenzoline, has been proven to attenuate pressure gradients in patients with $\mathrm{HCM}^{23,24}$ but we did not examine therapeutic options for right ventricular obstruction.

\section{References}

1. Frank S, Braunwald E. Idiopathic hypertrophic subaortic stenosis: Clinical analysis of 126 patients with emphasis on the natural history. Circulation 1968; 37: 759-788.

2. Maron BJ, Tajik AJ, Ruttenberg HD, Graham TP, Atwood GF, Victoria BE, et al. Hypertrophic cardiomyopathy in infants: Clinical features and natural history. Circulation 1982; 65: 7-17.

3. Casanova M, Gamallo C, Quero-Jimenez M, Garcia-Aguado A, Burgueros M, Garcia S, et al. Familial hypertrophic cardiomyopathy with unusual involvement of the right ventricle. Eur J Cardiol 1979; 9: $145-159$.

4. Barr PA, Celermajer JM, Bowdler JL, Cartmill TB. Idiopathic hypertrophic obstructive cardiomyopathy causing severe right ventricular outflow obstruction in infancy. Br Heart J 1973; 35: 1109-1115.

5. Morrow AG, Fisher RD, Fogarty TJ. Isolated hypertrophic obstruction to right outflow. Am Heart J 1969; 77: 814-817.

6. Lockhart A, Charpentier A, Bourdarias JP, Ben Ismail M, Outback P, Scebat L. Right ventricular involvement in obstructive cardiomyopathies: Hemodynamic studies in 13 cases. Br Heart J 1966; 28: 122 133.

7. Falcone DM, Moore D, Lambert EC. Idiopathic hypertrophic cardiomyopathy involving the right ventricle. Am J Cardiol 1967; 19: 735 740 .

8. Wigle ED, Marquis Y, Auger P. Muscular subaortic stenosis: Initial left ventricular inflow tract pressure in the assessment of intraventricular pressure differences in man. Circulation 1967; 35: 1100-1107.

9. Schwammental E, Block M, Schwartzkopff B, Losse B, Borggefe M, Schulte HD, et al. Prediction of the site and severity of obstruction in hypertrophic cardiomyopathy by color flow mapping and continuous wave Doppler echocardiography. J Am Coll Cardiol 1992; 20: $964-$ 972.

10. Blazer D, Kotler MN, Parry WR, Wertheimer J, Nakhjavan FK. Noninvasive evaluation of mid left ventricular obstruction by twodimensional and Doppler echocardiography and color flow Doppler echocardiography. Am Heart J 1987; 114: 1162-1168.

11. Sasson Z, Yock PG, Hatle LK, Alderman EL, Popp RL. Doppler echocardiographic determination of the pressure gradient in hyper- 
trophic cardiomyopathy. J Am Coll Cardiol 1988; 11: 752-756.

12. Panza JA, Petrone RK, Fananapazir L, Maron BJ. Utility of continuous wave Doppler assessment of left ventricular outflow tract pressure gradient in patients with hypertrophic cardiomyopathy. $J \mathrm{Am}$ Coll Cardiol 1992; 19: 91-99.

13. Falicov RE, Resnekov L, Bharati S, Lev M. Midventricular obstruction: A variant of obstructive cardiomyopathy. Am J Cardiol 1976; 37: 432-437.

14. Botti G, Tagliavini S, Bonatti V, Aurier E. Isolated hypertrophic obstructive cardiomyopathy of the right ventricle. G Ital Cardiol 1979; 9: 170-181.

15. Maron BJ, McIntosh CL, Klues HG, Cannon RO III, Roberts WC. Morphologic basis for obstruction to right ventricular outflow in hypertrophic cardiomyopathy. Am J Cardiol 1993; 71: 1089-1094.

16. Taylor RR, Bernstein L, Jose AD. Obstructive phenomena in ventricular hypertrophy. Br Heart J 1964; 26: 193-198.

17. Zoghbi WA, Haichin RN, Quinones MA. Midcavity obstruction in apical hypertrophy: Doppler evidence of diastolic intraventricular gradient with higher apical pressure. Am Heart J 1988; 116: $1469-$ 1474.

18. Nakamura T, Matsubara K, Furukawa K, Azuma A, Sugihara H, Katsume $\mathrm{H}$, et al. Diastolic paradoxic jet flow in patients with hypertrophic cardiomyopathy: Evidence of concealed apical asynergy with cavity obliteration. J Am Coll Cardiol 1992; 19: 516-524.
19. Fighali S, Krajcer Z, Edelman S, Leachman R. Progression of hypertrophic cardiomyopathy into a hypokinetic left ventricle: Higher incidence in patients with midventricular obstruction. J Am Coll Cardiol 1987; 9: 288-294.

20. McKenna WJ, Kleinebenne A, Nihoyannopoulos P, Foale R. Echocardiographic measurement of right ventricular wall thickness in hypertrophic cardiomyopathy: Relation to clinical and prognostic features. J Am Coll Cardiol 1988; 11: 351 - 358 .

21. Sherrid MV, Chu CK, Delia E, Mogtader A, Dwyer EM Jr. An echocardiographic study of the fluid mechanics of obstruction in hypertrophic cardiomyopathy. J Am Coll Cardiol 1993; 22: 816-825.

22. Shimizu M, Yokota Y, Kawai H, Terashima M, Sakuramoto H, Yokoyama M. Sonicated albumin for evaluating midventricular obstruction in hypertrophic cardiomyopathy. J Cardiol 1996; 27: 57-63 (in Japanese with English abstract).

23. Hiasa G, Hamada M, Shigematsu Y, Hara Y, Ohtsuka T, Ogimoto A, et al. Attenuation of biventricular pressure gradients by cibenzoline in an 18-year-old patient with hypertrophic obstructive cardiomyopathy. Circ J 2002; 66: 1173-1175.

24. Hamada M, Shigematsu Y, Hara Y, Suzuki M, Ohtsuka T, Hiasa G, et al. Antiarrhythmic drug, cibenzoline, can directly improve the left ventricular diastolic function in patients with hypertrophic cardiomyopathy. Jpn Circ J 2001; 65: 531-538. 